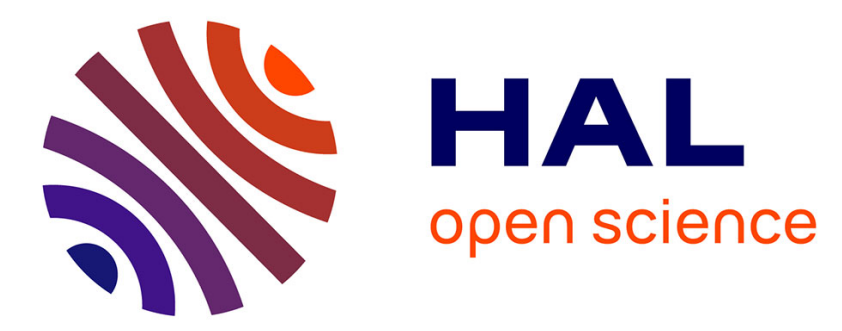

\title{
Impact of thermal gradients on the geometry correction of a bridge coordinate measuring machine
}

\author{
François Hennebelle, Thierry Coorevits, Salma El Asmai, Florence
}

Goutagneux, Renald Vincent

\section{- To cite this version:}

François Hennebelle, Thierry Coorevits, Salma El Asmai, Florence Goutagneux, Renald Vincent. Impact of thermal gradients on the geometry correction of a bridge coordinate measuring machine. Measurement Science and Technology, 2020, 10.1088/1361-6501/abbaa7 . hal-03481826

\section{HAL Id: hal-03481826 \\ https://hal.science/hal-03481826}

Submitted on 14 Feb 2022

HAL is a multi-disciplinary open access archive for the deposit and dissemination of scientific research documents, whether they are published or not. The documents may come from teaching and research institutions in France or abroad, or from public or private research centers.
L'archive ouverte pluridisciplinaire HAL, est destinée au dépôt et à la diffusion de documents scientifiques de niveau recherche, publiés ou non, émanant des établissements d'enseignement et de recherche français ou étrangers, des laboratoires publics ou privés. 


\title{
Impact of thermal gradients on the geometry correction of a bridge coordinate measuring machine
}

\author{
François Hennebelle $^{1}$ (D) Thierry Coorevits $^{2}$, Salma El Asmai ${ }^{3}$, Florence Goutagneux $^{3}$ \\ and Renald Vincent ${ }^{3}$ \\ ${ }^{1}$ DRIVE EA1859, Univ. Bourgogne Franche Comte, Nevers 58027, France \\ ${ }^{2}$ Mécanique, Surface, Matériaux et Procédés, MSMP-EA 7350, Arts et Métiers ParisTech, Lille 59800, \\ France \\ ${ }^{3}$ Centre Technique des Industries Mécaniques, 52 Avenue Félix Louat, Senlis 60300 France \\ E-mail: francois.hennebelle@u-bourgogne.fr
}

\begin{abstract}
If the problems related to the parts and measurement strategy of Coordinate Measuring Machines (CMMs) are not taken into consideration, temperature variations become the main source of measurement uncertainties. Indeed, they may cause variations in geometry as well as reference point drift. The effect of drift is sometimes minimized by CMM users and is not well quantified in general. The aim of this paper is to present a physical method to determine the evolution of CMM geometry and drift which is based directly on CMM temperature variations and construction parameters, i.e. the position of the axes measurement scales and reference points of each axis. The method is applied to a Zeiss CMM Contura G2. The consequences of these CMM evolutions are simulated in the measurement of a sphere generated by a Renishaw Machine Checking Gauge. The proposed method falls within the framework of an uncertainty assessment methodology performed by multi-level Monte Carlo simulation, where the first level corresponds to the characterization of the CMM evolution.
\end{abstract}

Keywords: drift, thermal errors, coordinate measuring machine (CMM), geometry evolution, uncertainty, metrology

\section{Introduction}

The first Coordinate Measuring Machines (CMMs) appeared in the 1960s [1]. The year 1973 was important in the development of CMMs, with the emergence of both the Zeiss UMM500, which can probably be considered the first modern CMM, as well as the TP1 Renishaw trigger probe. In the 1980s, the market for CMMs grew considerably. The most common type is the bridge CMM [2] consisting of granite rails and air bearings. Indeed, this configuration strikes a very good balance in terms of accessibility, geometric quality, capacity to fix the part directly on the machine and so on. The geometric quality of the CMM, initially obtained by honing the granite elements evolved considerably thanks to the introduction of numerical geometry correction [3]. Starting in the mid-1980s, the software underwent major improvements in terms of quality $[4,5]$ and validation of the algorithms [6-8].

The numerical correction of the CMM geometry is based on three assumptions: first of all, for each guideway, the moving part (bridge, carriage, ram) has a rigid body behavior, secondly, the rotation angles are so small that it is possible to write that the cosine is equal to 1 and the sine equal to the angle and, last, the description of geometrical errors of one guideway is independent of the others [9]. In [10], the notations for the description of the geometry are very strictly written and the assumptions for rigid body behavior are studied especially about the stiffness of the granite table. These assumptions work very well for a bridge machine but not, for 
example, for a moving ram horizontal-arm machine. For this kind of machine, it is necessary to complete the model. In this article, only bridge machines are considered and the three previous hypotheses are assumed to be valid for these machines.

Under these assumptions, six functions are necessary to describe the geometry of one guideway. In fact, for an horizontal guideway, the CMM defects can be called: linear positioning accuracy, horizontal straightness, vertical straightness, roll, pitch and yaw. Thus, this means that 18 functions are needed to describe the three guideways, to which three parameters (squareness) must be added.

On this basis, Kunzmann and al [11]. showed a metrological traceability chain between the realization of the measurement unit (meter) from its definition and the CMM thanks to the correction model and by means of a ball plate.

Since the 1990s, the evaluation of uncertainties has been the subject of a lot of published work [12-19]. Regarding uncertainties, the main ideas are contained in the documents of the Join Committee for Guides in Metrology, i.e. the GUM (JCGM 100) and supplement 2 (JCGM 102) for an analytical approach and supplement 1 (JCGM 101) [20] for a numerical approach (Monte-Carlo method) [12]. and many others proposed the concept of 'Virtual machine' which is a practical implementation of JCGM 101 for the CMMs [14]. is an approach by constraints, it is a system based on the Maximum Permissible Errors [21].

In the uncertainty budget due to the bridge machine, the geometry is (normally) a small contributor after correction. The most important contributors are thermal problems and (in bad situation) the probe (for example, a very long stylus on a touch trigger probe).

On CMMs and machine tools, thermal drift is a preponderant source of uncertainty and there are some articles addressing this [22-30]. In [30], Balsamo and al. described in six steps a method to correct the thermal effect. The present subject concerns the step B 'Selection of the thermal model' in the context of uncertainties assessment. In [25], the authors gave formulas to correct the effect of temperature but a more systematic model is proposed here about the effect of bending guideway, fixed point drift, expansion of scales and so on.

The rules of conception are quite different for a CMM compared with a machine-tool, a major reason is that the effort between the ball tip and the part is in the order of $0.2 \mathrm{~N}$. A CMM must be optimized to achieve excellent repeatability and reproducibility of results. A solution is to use the concept of isostatic coupling. The contact points are designed with an air bearing mounted fixed on a ball joint that provides the equivalent of a point with a frictionless movement. To design a CMM guideway, three contact points are using to make a plane support and two contact points to provide direction. The guideway is completed by a linear scale.

The first objective of this paper is to evaluate the possible and correlated evolution of all the defects of the CMM based directly on the design of the machine studied and thermal variations of the environment.

The second objective is to show that our method is part of a new approach of the concept of virtual machine named Multi Levels Monte Carlo Simulation (MLMCS). This new approach is intended to describe as precisely as possible the physic behavior of the CMM in order to take into account the covariances as accurately as possible. A summary of the possible complete modeling of a measurement process on CMMs will be presented in this paper.

To summarize, this paper deals with the physical determination of geometry and drift evolution of a CMM. It corresponds to the first level of the MLMCS used to evaluate uncertainties of any measurand on CMMs. The research was performed as part of a French accreditation group for the CETIM (Technical Center for Mechanical Industries).

\section{Subject and methods}

\subsection{Methodology}

The methodology, based on MLMCS [31], is described figure 1 . The 18 functions and three constants for squareness are determined to calibrate the bridge CMM. During these operations, the temperatures and the gradients are measured. A study of temperatures and gradients is carried out over a long period of time which allow to choose the probability distributions for the Monte Carlo simulations more representative and different to the calibration conditions. A reference correction can be implemented.

For each simulation, the bending and the dilatation of the guideways and of the mechanical structure can be estimated. With these data, the displacements of the aerostatic bearings and the evolution of the scales are calculated and so, the modification of the error components which describe the geometry of the CMM. This means that the drift is directly integrated with the CMM geometrical evolutions during the simulations.

\subsection{Definition of the machine coordinate system}

ISO 10360 is the reference standard for the CMM. In 10 360-1 [1], neither the order nor the names of the axes were defined. It is even noted, after the schematic diagram in Annex I, Figure A.2 that 'The indicated directions are given for information only. Other approaches exist'. In fact, there are several designations for CMM axes according to the manufacturer of the machine.

In France, the classical denomination of the CMM axes was given in the NF E 11-151 [32] standard. This standard, which had the advantage of standardizing the ratings, was suppressed in 2003 due to lack of actual use. Therefore, each manufacturer uses its own conventions. The lack of uniqueness of the notations is a notable constraint for the development of a standard software. The notations of the CMM axes defined in this earlier standard will be used in this paper. It is interesting to note that VCMM developers [12,13] have made the same choice.

The standard refers to $\mathrm{X}$ as the work piece holder (or the slide directly connected to the work piece holder), $\mathrm{Z}$ as the probe holder and the $\mathrm{Y}$ axis as the complementary axis. The use of $\mathrm{X}, \mathrm{Y}, \mathrm{Z}$ is a direct coordinate system that makes it possible to create a standard system, regardless of the CMM, a noted universal coordinate system. 
Parameters of level\#1.1 - Monte Carlo Thermal variations estimated around the CMM (Figure 5 and table 5)

\begin{tabular}{|c|}
\hline $\begin{array}{c}\text { Potential correction of } \\
\text { the CMM geometry }\end{array}$ \\
Measurement of \\
temperature variations \\
\hline
\end{tabular}

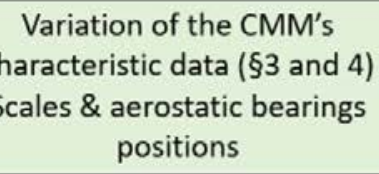

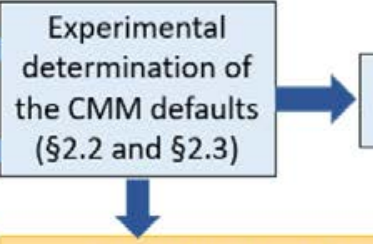

Uncertainties on the CMM defaults

Simulation level\#2 - Monte Carlo Part evolutions and measurands evaluation

Bending \& Dilatation effects
on the CMM
Guideways and mechanical
structure (\$2.4)

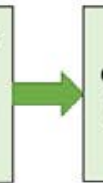

\section{ch}

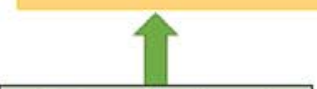

Determination of possible changes in the CMM geometry (Appendices I to III)
Level\#1.2 - Monte Carlo Probe simulation

Figure 1. Schematization of the method.

The coordinate system used by Zeiss on the CMM studied (CONTURA G2) is referenced as the machine tool coordinate system, but it does not correspond to the universal coordinate system defined (figure 2).

To convert any coordinate system to the defined universal coordinate system, one simply has to write the corresponding homogeneous transformation matrix. Thus the transformation from ZEISS coordinates to universal coordinates is written: $\left(\begin{array}{ccc}0 & -1 & 0 \\ 1 & 0 & 0 \\ 0 & 0 & 1\end{array}\right)\left(\begin{array}{l}x \\ y \\ z\end{array}\right)=\left(\begin{array}{c}-y \\ x \\ z\end{array}\right)$.

\subsection{Geometric evaluation of $C M M$}

2.3.1. Generalities and recommendations To check the 3D geometry of a CMM, there are several well-known methods today, namely:

- Sphere plate artifact.

- Direct interferometry and electronic levels for rotations (conventionally used by manufacturers).

- Laser tracer (currently being evaluated).

- Step gauge and rule (used for French accreditation by the authors for the CETIM for example).

Machine geometry is generally characterized by 18 functions and 3 perpendicularities, schematized in figure 3. Other functions can be added for some machines having, because of their construction, variations of roll or pitch, for example. The objective is to physically represent the defects of the machine. So, it is not conceivable to interpolate each defect of the CMM by too high degree polynomial functions in order to approach the physical geometry of the machine. This must also be decoupled from other aspects related to the automatic control or errors of determination. Therefore, it is optimal to interpolate the variations of the defects of the CMM due to thermal phenomena by a low-level polynomial, a degree of 3 is sufficient [33]. The periodic systematic errors can be taken into account by Fourier series functions calculated on the residues of the function defects of the CMM. Nevertheless, it is important to perform repeatability on each of the geometrical functions of the CMM.

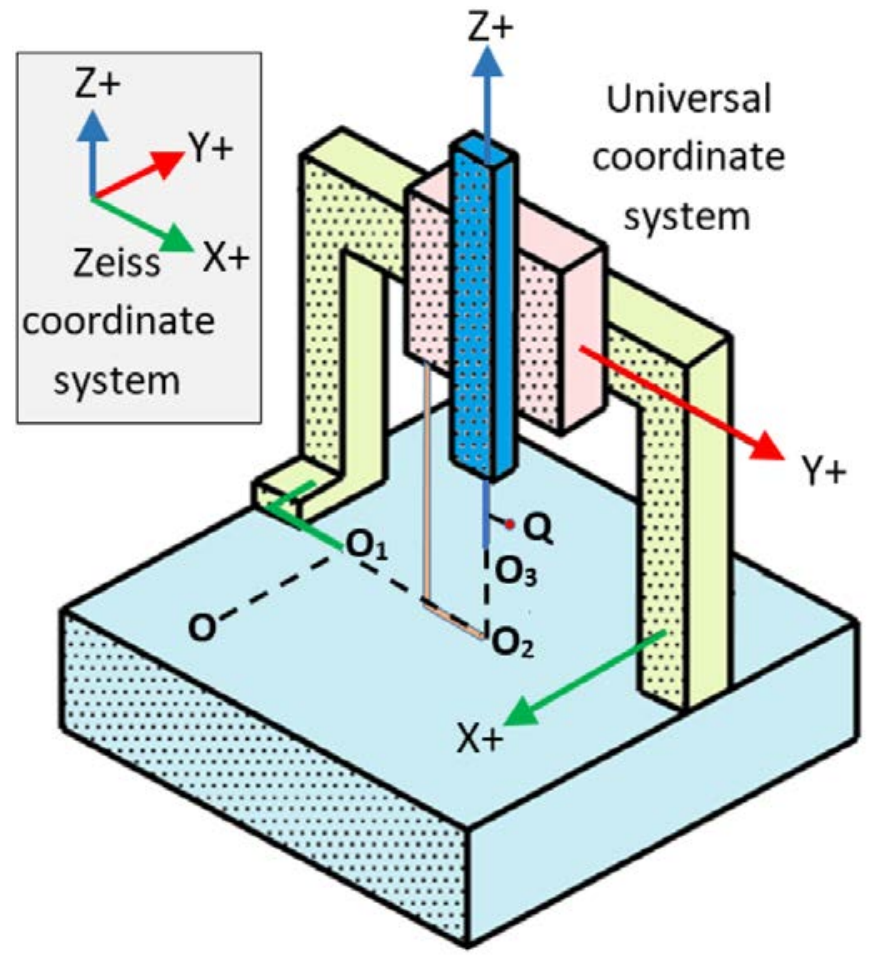

Figure 2. Zeiss coordinate system based on machine tool coordinate system compared to the universal coordinate system.

Indeed, on a CMM, it is conventional to have periodic systematic errors due to, for example, the recirculating ball screw mechanism defects. Nevertheless, not all periodic errors are repeatable, notably linked to stick-slip and hysteresis. Theses periodic non-repeatable errors are then taken into account in uncertainties.

2.3.2. Setting up geometry and conventions With the definition of the axes presented in $\$ 2.2$, the machine's geometry can be implemented. So, in figure 2, point $\mathrm{Q}$ is at the center of the ball of the working probe. Points $\mathrm{O}_{1}, \mathrm{O}_{2}$ and $\mathrm{O}_{3}$ are defined so that point $\mathrm{O}_{3}$ belongs to the $\mathrm{Z}$ probe-bearing axis. Point $\mathrm{O}_{3}$ 


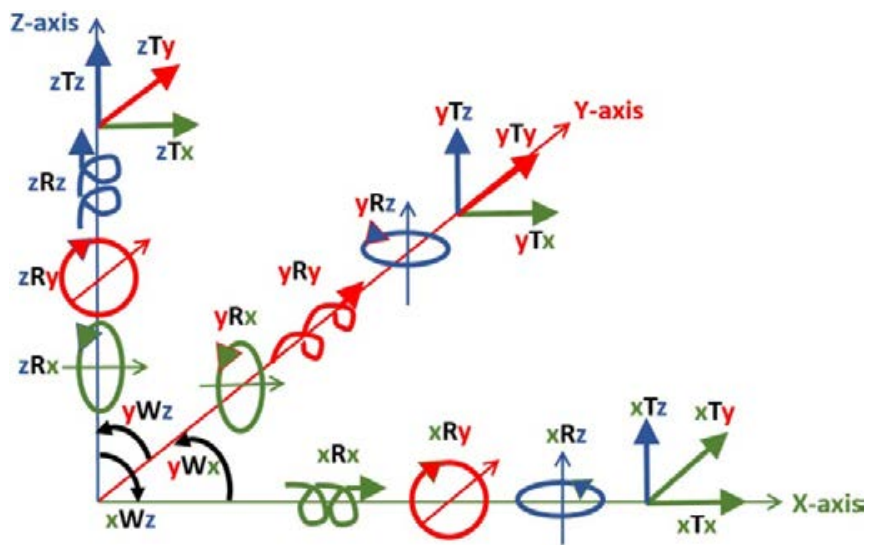

Figure 3. Schematic representation of CMM defects.

is, by convention, the center of the ball of a theoretical probe whose lever arm $\mathrm{O}_{3} \mathrm{Q}$ is zero, that is to say on the axis of the slide. Point $\mathrm{O}_{2}$ coincides with point $\mathrm{O}_{3}$ when the dimension $Z$ is zero. Point $\mathrm{O}_{1}$ coincides with point $\mathrm{O}_{3}$ when $Y$ and $Z$ are null. This type of notation has been used by Zhang et al since 1985 [10].

With these notations, rotation and translation vectors for the $X$-axis could be noted in equation (1) and (2) respectively:

$$
\overrightarrow{w_{x}}=(x R x, x R y, x R z)=(\text { roll }, \text { pitch }, y a w)
$$

$$
\vec{\varepsilon}_{O_{1}}=(x T x, x T y, x T z)=
$$

(linear accuracy error, straightness, straightness).

The same principle applies to $Y$ and $Z$ axes.

The perpendicularity is then corrected and taken into account by adding a constant on the following rotations:

- $x R z$ : perpendicularity between $X$ and $Y$ axes.

- $y R x$ : perpendicularity between $Y$ and $Z$ axes.

- $x R y$ : perpendicularity between $Z$ and $X$ axes.

The basic idea for modeling geometry of a bridge CMM is based on the assumption of the mechanics of the solid body, that is to say that each axis behaves like a solid, moving independently of others. Therefore, with the positions of $\mathrm{O}_{1}, \mathrm{O}_{2}, \mathrm{O}_{3}$ and $Q$ defined in figure 2 and the formalism of torsors, the contribution to displacement of point $Q$ linked to axes $X, Y$ and $Z$ respectively is expressed in the equations (3) and (4).

$$
\begin{aligned}
& \vec{\varepsilon}_{x}(Q)=\vec{\varepsilon}_{\left(O_{1}\right)}+\vec{w}_{x} \Lambda \overrightarrow{O_{1} Q} \\
& \vec{\varepsilon}_{y}=\vec{\varepsilon}_{(Q)}+\vec{w}_{y} \Lambda \overrightarrow{O_{2} Q} \\
& \vec{\varepsilon}_{z}(Q)=\vec{\varepsilon}_{\left.z_{(O}\right)}+\vec{w}_{z} \Lambda \overrightarrow{O_{3} Q} .
\end{aligned}
$$

As a result, the global displacement is:

$$
\vec{\varepsilon}_{(Q)}=\vec{\varepsilon}_{(Q)}+\vec{\varepsilon}_{y}(Q)+\vec{\varepsilon}_{z}(Q) .
$$

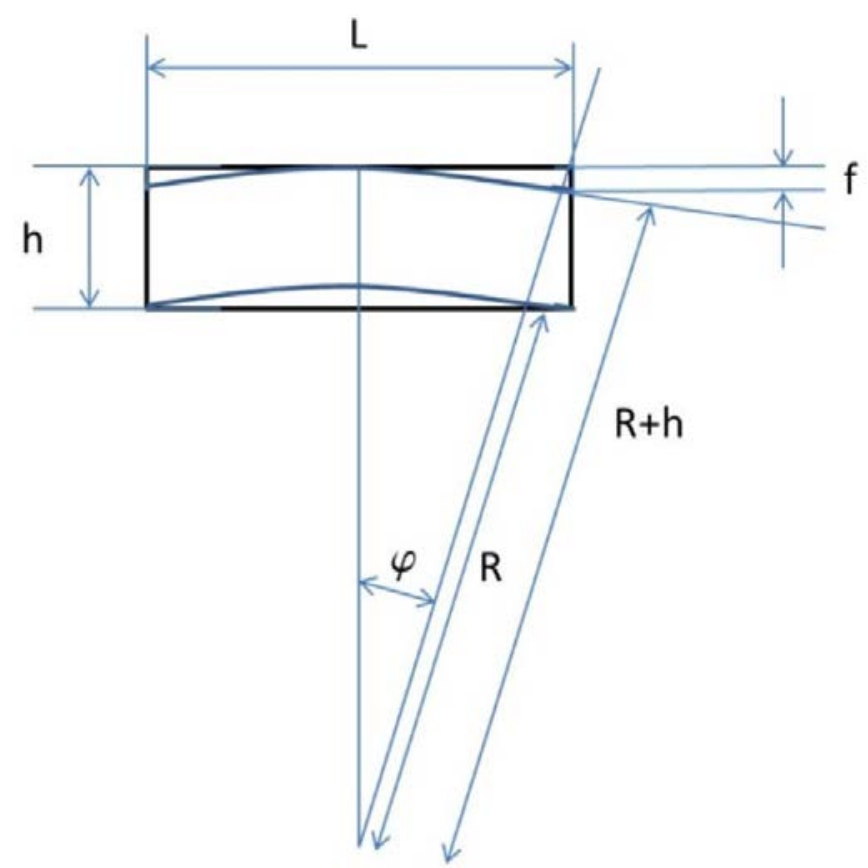

Figure 4. Parametrization for deformation calculation.

\subsection{Model for deforming CMM structures}

The purpose of this section is to determine the function governing the deformation of a beam subjected to a temperature gradient. In fact, CMM guideways are subject to bending effects related to temperature variations.

So, the equation of heat propagation by conduction, according to Fourier, in stationary thermal conditions, is written: $d^{2} T / d x^{2}=0$. With this hypothesis, if a beam has a temperature difference $\Delta T$ between one face and the other, the temperature distribution is linear.

Assuming that the bottom of the solid is at the reference temperature and corresponds to the length $L$ then, with the notations of the figure 4 , the equation (5) can be written.

$$
L=2 R \varphi
$$

The equation (6) is written for the upper fiber.

$$
L+\alpha L \Delta T=2(R+h) \varphi .
$$

In this equation (6), $\alpha$ is the coefficient of thermal expansion and $h$ the granite height.

The difference between the equation (5) and (6) allows to obtain the equation (7)

$$
\alpha L \Delta T=2 h \varphi
$$

In this model, the bending $f$ (figure 4 ) could be defined by the equation (8)

$$
f=(R+h)(1-\cos (\varphi)) .
$$




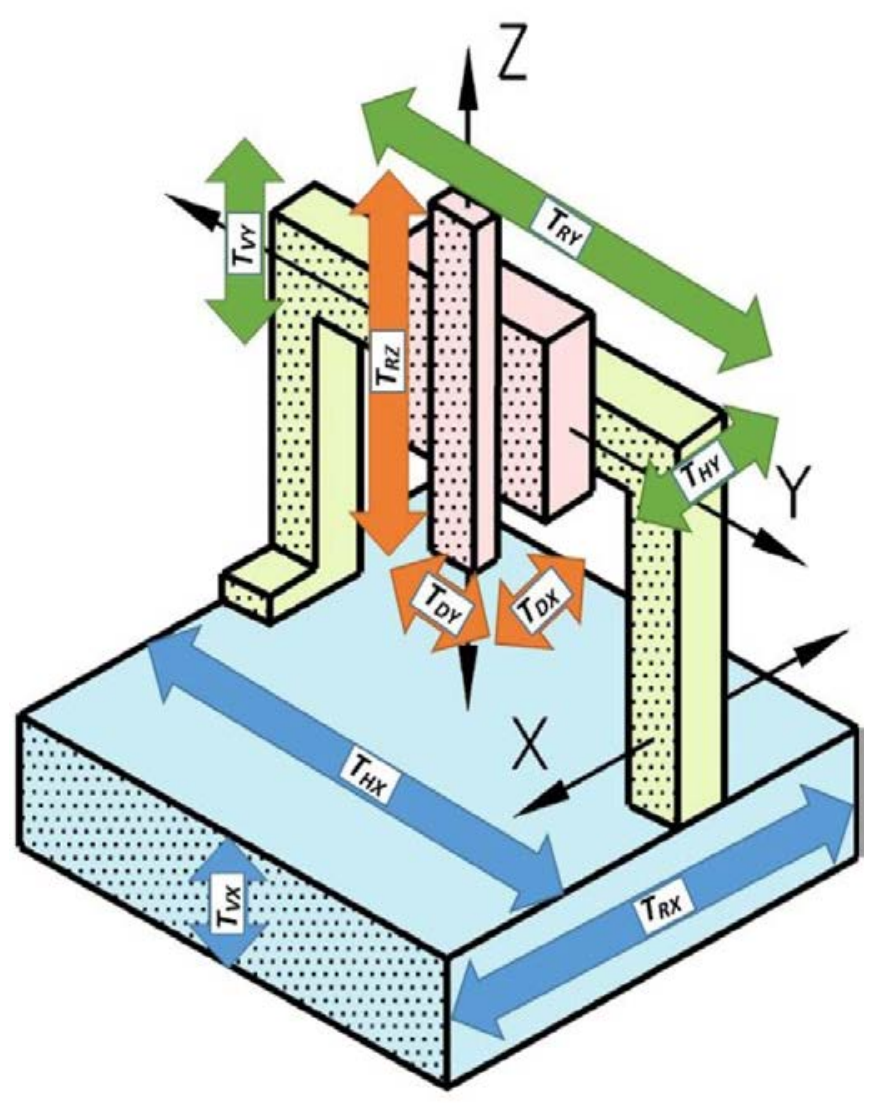

Figure 5. Characterization of the gradients and temperature variations.

Using Taylor simplification $(\mathrm{h} \ll \mathrm{R})$, the equation (8) can be simplified to obtain the approximate bending $f$, defined in the equation (9).

$$
f \approx R \frac{\varphi^{2}}{2}=\frac{\alpha L^{2} \Delta T}{8 h} .
$$

With the assumption that the deformation of the granite is parabolic and that the bending is maximum and has a value $f$ in the middle of the granite, the vertical bending in the $X$-axis at a $\mathrm{x}$ position can be defined by the equation (10).

$$
\frac{\alpha L^{2} \Delta T}{8 h}\left(1-\left(\frac{2 x}{L}\right)^{2}\right) .
$$

To be able to evaluate the deformations, it is necessary to note the dimensions of the main elements of the CMM (table 1) and identify the thermal variations to measure (figure 5).

\section{Characteristic data of the CMM}

\subsection{Points governing the geometry of the machine}

For each axis of a CMM, there are five degrees of freedom fixed. Therefore, the guiding of the CMM must be taken into account for five characteristic points. In general, three points constitute a plane and two other aligned with the axis constitute an annular linear connection. These points $\left(P_{1 x}\right.$ to $P_{5 x}$ for

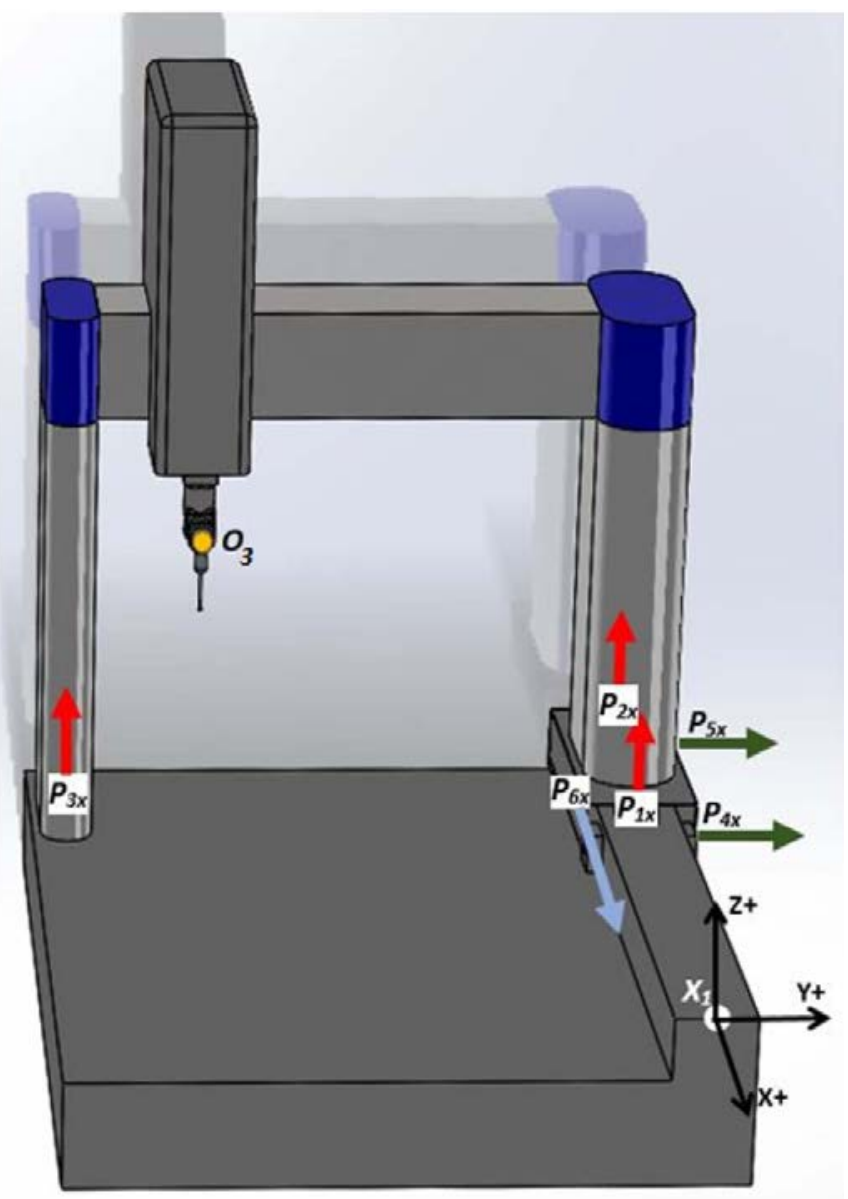

Figure 6. Explanation of the reference points to the $X$ axis.

the $X$-axis for example) are related directly to the aerostatic bearings or the guiding device used.

A sixth point ( $P_{6 x}$ for example for the $X$-axis) is associated to correspond to the position of the reading head on the scale, when the axis in question is at its original position.

A point $O_{i}$ corresponds to the position of the point at the end of the reference probe. It is important to note that the positions are measured from a fixed point (figure 6) on the axis under consideration, i.e. the fixed point of the linear scale.

These reference points $\left(P_{1 i}\right.$ to $P_{5 i}$ with $\mathrm{i}$ is the considered axis) are important because they directly contribute to the geometry of the machine. The first step is to identify them. Then, depending on the deformations of the structure due to the effect of gradients and thermal expansion, it is possible to know physically the evolution of the geometry of the machine.

\subsection{X-axis reference points}

Figure 6 is a schematic representation of the CMM studied. In this figure, the reference points are identified for the $X$-axis.

Consequently, for the characterization of the guiding along the $X$-axis, note:

- $P_{1 x}$ and $P_{2 x}$ are the two aerostatic bearings of normal $Z$ on the guideway of the conventional $X$-axis of the machine (main driving side of the axis-right of bridge). P1x is the 
Table 1. Building materials and dimensions of the elements-Zeiss Contura G2.

\begin{tabular}{lllllll}
\hline \multirow{2}{*}{ Axis considered } & \multicolumn{2}{l}{ Dimensions of the axis $(\mathrm{mm})$} & $\begin{array}{l}\text { Material of the } \\
\text { considered axis }\end{array}$ & $\begin{array}{l}\text { Thermal expansion } \\
\text { coefficient of the entity }\left(\mathrm{K}^{-1}\right)\end{array}$ & $\begin{array}{c}\text { Thermal expansion } \\
\text { coefficient of the scale }\left(\mathrm{K}^{-1}\right)\end{array}$ \\
\cline { 2 - 6 } & Along $X$ & Along $Y$ & Along $Z$ & $\propto_{\mathrm{x}}=6.010^{-6}$ & $\propto_{R x}=510^{-8}$ \\
$X$ & $L_{X}=1650$ & $H_{H X}=1185$ & $H_{V X}=205$ & Granite & $\propto_{\mathrm{y}}=3,910^{-6}$ & $\propto_{R y}=510^{-8}$ \\
$Y$ & $H_{H Y}=76$ & $L_{Y}=1140$ & $H_{V Y}=203$ & Ceramic & $\propto_{\mathrm{z}}=3,910^{-6}$ & $\propto_{R z}=510^{-8}$ \\
\hline
\end{tabular}

aerostatic bearing closest to $\mathrm{X}_{1}$. The $X$-axis guideway is positioned on the right side of the $\mathrm{XY}$ granite. The guideway protrudes $60 \mathrm{~mm}$ laterally (outer right side).

- $P_{3 x}$ corresponds to the aerostatic bearing of normal $Z$ under the left jamb of the bridge.

- $P_{4 x}$ and $P_{5 x}$ are the 2 lateral bearings of normal $Y$ on the guideway of the conventional $X$ axis of the machine (main driving side of the axis-right jamb of the bridge). $P_{4 x}$ is the bearing closest to $\mathrm{X}_{1}$.

- $\mathrm{P}_{6 \mathrm{x}}$ is the position of the $X$-axis scale (reference of the encoder of the scale). This scale is positioned on the guideway along the $X$-axis.

\subsection{Reference entities of the CMM}

The same method is used for the $Y$ and $Z$ axis as for the $X$-axis.

Table 2 summarizes the characteristic points of the CMM studied and the normal vectors associated at these points.

\section{Consistent determination of the evolution of machine defects}

\subsection{Bending effect and axes thermal expansion}

The bending and dilatation effects on the axes are summarized in table 3. Hence, the thermal deformations of the machine result from the 9 thermal variations identified (figure 5).

\subsection{Effects of thermal variations on the $X$-axis}

The principle involves considering that the displacement of the characteristic points of the axis (the bearings $P_{1 x}$ to $P_{5 x}$ and the reading head of the scale $P_{6 x}$ ) corresponds to six small displacements which are expressed with the point considered, that is to say in $O_{1}$ for the $\mathrm{X}$ axis, $O_{2}$ for the $\mathrm{Y}$ axis and $O_{3}$ for the $Z$ axis.

In this way, with the equations defined at $\$ 2.3 .2$., the equation (11) is the expression of the torsor in $O_{1}$ of the different points $P_{i x}$ for the $X$-axis.

$$
\overrightarrow{\varepsilon\left(P_{i}\right)}=\left|\begin{array}{l|l}
x \operatorname{Tx}(x) \\
x \operatorname{Ty}(x) \\
x \operatorname{Tz}(x)
\end{array}+\right| \begin{aligned}
& x R x(x) \\
& x R y(x) \\
& x R z(x)
\end{aligned} \quad \Lambda \vec{O}_{1} P_{i} \text { with } i \in\{1,6\} .
$$

4.2.1. Effects of $T_{V X}$ on the $X$-axis defects With table 3 and the equation (10), it is then possible to solve the series of 6 equations which makes it possible to determine the $T_{V X}$ influence on the defects of the $X$-axis of the machine. This is described in the system of equations (12)

$$
\left\{\begin{array}{c}
\frac{\propto_{x} \cdot L_{X}^{2} T_{V X}}{8 H_{V X}}\left(1-\left(\frac{\overrightarrow{X_{1} P_{i x}} \cdot \overrightarrow{n_{x}}+x-\frac{L_{X}}{2}}{\frac{L_{X}}{2}}\right)^{2}\right) \\
=\left(\overrightarrow{\varepsilon_{O_{1}}}+\overrightarrow{w_{x}} \Lambda \overrightarrow{O_{1} P_{i x}}\right) \cdot \overrightarrow{n_{P i x}} \\
\text { with } \mathrm{i}=\{1 \text { to } 3\} \text { and } \overrightarrow{n_{P i x}}=\overrightarrow{n_{z}} \\
0=\left(\vec{\varepsilon}_{O_{1}}+\overrightarrow{w_{x}} \Lambda \overrightarrow{O_{1} P_{i x}}\right) \cdot \overrightarrow{n_{P i x}} \\
\text { with } \mathrm{i}=\{4 \text { to } 5\} \text { and } \overrightarrow{n_{P i x}}=\overrightarrow{n_{y}} \\
=\left(\overrightarrow{\varepsilon_{O_{1}}}+\overrightarrow{w_{x}} \Lambda \overrightarrow{O_{1} P_{6 x}}\right) \cdot \overrightarrow{n_{P 6 x}} \\
\text { with } \overrightarrow{n_{P 6 x}}=\overrightarrow{n_{x}} .
\end{array}\right.
$$

Thus, the $T_{V X}$ effects on the defects $x T x, x T y, x T z, x R x, x R y$, $x R z$, calculated with the real data of the CMM studied, are shown in table 4 . It is interesting to note that $T_{V X}$ has no influence on the yaw $x R z$.

4.2.2. Effects of $T_{H X}$ on the $X$-axis defects From table $3, T_{H X}$ influence on the defects of the $X$-axis is obtained by the resolution of the system of equations (13)

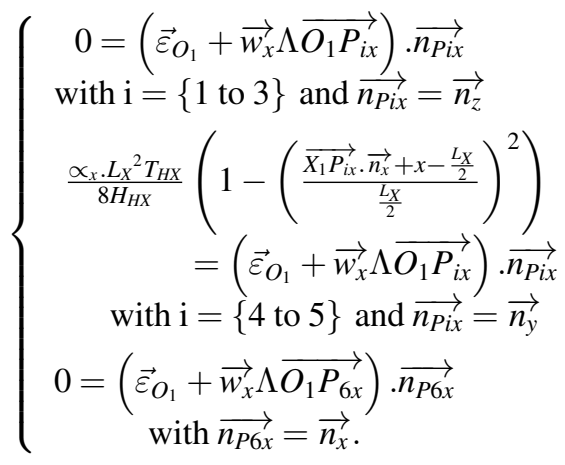

Thus, $T_{H X}$ effects on $x T x, x T y, x T z, x R x, x R y, x R z$ are shown in table 4. It is important to note that only the accuracy error on the axis, the Y-straightness and the yaw are impacted by $\mathrm{T}_{\mathrm{HX}}$. 
Table 2. Characteristic points of the CMM studied-Zeiss Contura G2.

\begin{tabular}{|c|c|c|c|c|c|c|c|}
\hline \multirow{2}{*}{ Axis considered } & \multirow{2}{*}{ Reference entities } & \multicolumn{3}{|c|}{ Conventional local coordinates } & \multicolumn{3}{|c|}{ Associated conventional normals } \\
\hline & & $X(\mathrm{~mm})$ & $Y(\mathrm{~mm})$ & $Z(\mathrm{~mm})$ & $\mathrm{n}_{\mathrm{X}}$ & $\mathrm{n}_{\mathrm{Y}}$ & $\mathrm{n}_{\mathrm{Z}}$ \\
\hline \multirow{7}{*}{$\mathbf{X}$} & Point $O_{1}$ & -1230 & -920 & 575 & - & - & - \\
\hline & Aerostatic Bearing $P_{1 x}$ & $-1077,5$ & 0 & 0 & 0 & 0 & 1 \\
\hline & Aerostatic Bearing $P_{2 x}$ & $-1547,5$ & 0 & 0 & 0 & 0 & 1 \\
\hline & Aerostatic Bearing $P_{3 x}$ & -1312.5 & -1117.5 & -120 & 0 & 0 & 1 \\
\hline & Aerostatic Bearing $P_{4 x}$ & $-1077,5$ & 85 & -43 & 0 & 1 & 0 \\
\hline & Aerostatic Bearing $P_{5 x}$ & $-1547,5$ & 85 & -43 & 0 & 1 & 0 \\
\hline & $P_{6 x}:$ Scale $\mathrm{X}$ & -1205 & -67 & -100 & 1 & 0 & 0 \\
\hline \multirow{7}{*}{$\mathbf{Y}$} & Point $\mathrm{O}_{2}$ & 140 & 230 & -380 & - & - & - \\
\hline & Aerostatic Bearing $P_{l y}$ & -38.5 & 102 & 0 & 0 & 0 & 1 \\
\hline & Aerostatic Bearing $P_{2 y}$ & -38.5 & 339 & 0 & 0 & 0 & 1 \\
\hline & Aerostatic Bearing $P_{3 y}$ & 0 & 220.5 & -42.5 & 1 & 0 & 0 \\
\hline & Aerostatic Bearing $P_{4 y}$ & 0 & 175.5 & -160.5 & 1 & 0 & 0 \\
\hline & Aerostatic Bearing $P_{5 y}$ & 0 & 265.5 & -160.5 & 1 & 0 & 0 \\
\hline & $P_{6 y}:$ Scale Y & -76 & 371 & -100 & 0 & 1 & 0 \\
\hline \multirow{7}{*}{2} & Point $\mathrm{O}_{3}$ & -31.5 & 31.5 & -145 & - & - & - \\
\hline & Aerostatic Bearing $P_{1 z}$ & -31.5 & 0 & 410 & 0 & -1 & 0 \\
\hline & Aerostatic Bearing $P_{2 z}$ & -15.5 & 0 & 215 & 0 & -1 & 0 \\
\hline & Aerostatic Bearing $P_{3 z}$ & -47.5 & 0 & 215 & 0 & -1 & 0 \\
\hline & Aerostatic Bearing $P_{4 z}$ & -63 & 31.5 & 215 & -1 & 0 & 0 \\
\hline & Aerostatic Bearing $P_{5 z}$ & -63 & 31.5 & 410 & -1 & 0 & 0 \\
\hline & $P_{6 z}:$ Scale Z & -31.5 & 0 & 270 & 0 & 0 & 1 \\
\hline
\end{tabular}

Table 3. Bending effects and axes dilatations.

\begin{tabular}{|c|c|c|c|}
\hline \multirow{2}{*}{$\begin{array}{l}\text { Thermal } \\
\text { Variations }\end{array}$} & \multicolumn{2}{|c|}{ Bending effect } & \multirow{2}{*}{$\begin{array}{l}\text { Dilatation effect } \\
\text { on the axis }\end{array}$} \\
\hline & $\begin{array}{l}\text { Bending } \\
\text { Value }\end{array}$ & $\begin{array}{l}\text { Points directly } \\
\text { impacted }\end{array}$ & \\
\hline$T_{V X}$ & $\frac{\propto_{x} \cdot L_{X}^{2} \cdot T_{V X}}{8 \cdot H_{V X}}$ & $\begin{array}{l}P_{1 x}\left(\vec{n}_{z}\right) \\
P_{2 x}\left(\vec{n}_{z}\right) \\
P_{3 x}\left(\vec{n}_{z}\right)\end{array}$ & \\
\hline$T_{H X}$ & $\frac{\propto_{x} \cdot L_{x}^{2} \cdot T_{H X}}{8 \cdot H_{H X}}$ & $\begin{array}{l}P_{4 x}\left(\vec{n}_{y}\right) \\
P_{5 x}\left(\vec{n}_{y}\right)\end{array}$ & \\
\hline$T_{R X}$ & & & $\propto_{R x} \cdot T_{R X} \cdot x$ \\
\hline$T_{V Y}$ & $\frac{\propto_{y} \cdot L_{y}^{2} \cdot T_{V Y}}{8 \cdot H_{V Y}}$ & $\begin{array}{l}P_{1 y}\left(\vec{n}_{z}\right) \\
P_{2 y}\left(\vec{n}_{z}\right) \\
P_{3 y}\left(\vec{n}_{z}\right)\end{array}$ & \\
\hline$T_{H Y}$ & $\frac{\propto_{y} \cdot L_{x}^{2} \cdot T_{H Y}}{8 \cdot H_{H Y}}$ & $\begin{array}{l}P_{4 y}\left(\vec{n}_{x}\right) \\
P_{5 y}\left(\vec{n}_{x}\right)\end{array}$ & \\
\hline$T_{R Y}$ & & & $\propto_{R y} \cdot T_{R Y \cdot y}$ \\
\hline$T_{D X}$ & $\frac{\propto_{z} \cdot L_{Z}^{2} \cdot T_{D X}}{8 \cdot H_{D X}}$ & $\begin{array}{l}P_{1 z}\left(\vec{n}_{y}\right) \\
P_{2 z}\left(\vec{n}_{y}\right) \\
P_{3 z}\left(\vec{n}_{y}\right)\end{array}$ & \\
\hline$T_{D Y}$ & $\frac{\propto_{z} \cdot L_{Z}^{2} \cdot T_{D Y}}{8 \cdot H_{D Y}}$ & $\begin{array}{l}P_{4 z}\left(\vec{n}_{x}\right) \\
P_{5 z}\left(\vec{n}_{x}\right)\end{array}$ & \\
\hline$T_{R Z}$ & & & $\propto_{R z} \cdot T_{R Z \cdot z}$ \\
\hline
\end{tabular}

4.2.3. Effects of $T_{R X}$ on $X$-axis defects The $T_{R X}$ effects could be obtained by solving the system of equations (14)

$$
\left\{\begin{array}{c}
0=\left(\vec{\varepsilon}_{O_{1}}+\overrightarrow{w_{x}} \Lambda \overrightarrow{O_{1} P_{i x}}\right) \cdot \overrightarrow{n_{P i x}} \\
\text { with } \mathrm{i}=\{1 \text { to } 3\} \text { and } \overrightarrow{n_{P i x}}=\overrightarrow{n_{z}} \\
0=\left(\overrightarrow{\varepsilon_{O_{1}}}+\overrightarrow{w_{x}} \Lambda \overrightarrow{O_{1} P_{i x}}\right) \cdot \overrightarrow{n_{P i x}} \\
\text { with } \mathrm{i}=\{4 \text { to } 5\} \text { and } \overrightarrow{n_{P i x}}=\overrightarrow{n_{y}} \\
\propto_{R x} \mathrm{~T}_{R X} x=\left(\overrightarrow{\varepsilon_{O_{1}}}+\overrightarrow{w_{x}} \Lambda \overrightarrow{O_{1} P_{6 x}}\right) \cdot \overrightarrow{n_{P 6 x}} \\
\text { with } \overrightarrow{n_{P 6 x}}=\overrightarrow{n_{x}} .
\end{array}\right.
$$

However, it is evident that $\mathrm{T}_{\mathrm{RX}}$ only has an influence on the linear $x T x$ defect. The result is given in table 4.

\subsection{Effects of thermal variations on the $Y$ and Z-axis}

The same resolution of the $X$-axis is performed on the $Y$ and $Z$ axis. The results, applied to the CMM studied, are stored directly in table 4.

\subsection{Summary of the effects on the thermal variations}

To sum up, in order to characterize the evolution on the CMM, it is necessary to solve nine series of six equations. Table 4 summarizes the different effects of thermal variations on the evolution of the CMM defects. The values in the Table correspond to the polynomial coefficients used to take into account the changes in the geometry of the machine. It is necessary to multiply these coefficients by the term of the corresponding temperature, measured in the area around 
Table 4. Impact on the CMM defects and value associed in $\mathrm{mm} \cdot \mathrm{K}^{-1}$ for each thermal variations.

\begin{tabular}{|c|c|c|c|c|c|c|c|c|}
\hline & & & \multicolumn{6}{|c|}{ Impacted defects taken into account by second degree polynomial fonctions } \\
\hline & & & $\mathbf{x T x}$ & $\mathbf{x T y}$ & $\mathbf{x T z}$ & $\mathbf{x R x}$ & $\mathbf{x R y}$ & $\mathbf{x R z}$ \\
\hline \multirow{9}{*}{ 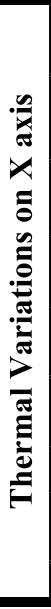 } & \multirow{3}{*}{$\stackrel{x}{4}$} & 0 & $\begin{array}{c}\text { Drift } \\
-4.22287 \mathrm{e}-2\end{array}$ & $\begin{array}{c}\text { Drift } \\
4.46935 \mathrm{e}-4\end{array}$ & $\begin{array}{c}\text { Drift } \\
-5.18832 \mathrm{e}-2 \\
\end{array}$ & $\begin{array}{c}\text { Constant rotation } \\
-7.23195 \mathrm{e}-7 \\
\end{array}$ & $\begin{array}{c}\text { Perpendicularity } \\
-6.2561 \mathrm{e}-5 \\
\end{array}$ & \\
\hline & & 1 & $\begin{array}{c}\text { Linear accuracy } \\
1.97561 \mathrm{e}-5\end{array}$ & & $\begin{array}{c}\text { Perpendicularity } \\
6.01463 \mathrm{e}-5\end{array}$ & & $\begin{array}{l}\text { Bending X } \\
2.92683 \mathrm{e}-8\end{array}$ & \\
\hline & & 2 & & & $\begin{array}{c}\text { Vertical bending } \\
-1.46341 \mathrm{e}-8 \\
\end{array}$ & & & \\
\hline & \multirow{3}{*}{$\stackrel{x}{\mu}$} & 0 & $\begin{array}{c}\text { Drift } \\
9.23184 \mathrm{e}-3\end{array}$ & $\begin{array}{c}\text { Drift } \\
-9.09068 \mathrm{e}-3\end{array}$ & & & & $\begin{array}{c}\text { Perpendicularity } \\
1.08228 \mathrm{e}-5\end{array}$ \\
\hline & & 1 & $\begin{array}{c}\text { Linear accuracy } \\
-4.31899 \mathrm{e}-6\end{array}$ & $\begin{array}{c}\text { Perpendicularity } \\
1.04051 \mathrm{e}-5\end{array}$ & & & & $\begin{array}{c}\text { Bending Y } \\
-5.06329 \mathrm{e}-9\end{array}$ \\
\hline & & 2 & & $\begin{array}{l}\text { Horizontal bending } \\
-2.53165 \mathrm{e}-9\end{array}$ & & & & \\
\hline & \multirow{4}{*}{$\stackrel{\check{z}}{=}$} & 0 & & & & & & \\
\hline & & 1 & $\begin{array}{c}\text { Linear accuracy } \\
5.00000 \mathrm{e}-8\end{array}$ & & & & & \\
\hline & & 2 & & & & & & \\
\hline & & & $\mathbf{y T x}$ & yTy & $\mathbf{y T z}$ & $\mathbf{y R x}$ & yRy & $\mathbf{y R z}$ \\
\hline \multirow{9}{*}{ 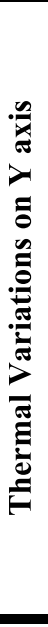 } & \multirow{3}{*}{3} & 0 & & $\begin{array}{c}\text { Drift } \\
1.88007 \mathrm{e}-3\end{array}$ & $\begin{array}{c}\text { Drift } \\
1,8765 \mathrm{e}-3\end{array}$ & $\begin{array}{c}\text { Perpendicularity } \\
6.71453 \mathrm{e}-6 \\
\end{array}$ & & \\
\hline & & 1 & & $\begin{array}{l}\text { Linear accuracy } \\
-5.37931 \mathrm{e}-6\end{array}$ & $\begin{array}{l}\text { Perpendicularity } \\
6.53202 \mathrm{e}-6\end{array}$ & $\begin{array}{c}\text { Bending Y } \\
-1.92118 \mathrm{e}-8\end{array}$ & & \\
\hline & & 2 & & & $\begin{array}{l}\text { Vertical Bending } \\
-9.60591 \mathrm{e}-9\end{array}$ & & & \\
\hline & \multirow{3}{*}{$\exists$} & 0 & $\begin{array}{c}\text { Drift } \\
1.50359 \mathrm{e}-3\end{array}$ & $\begin{array}{c}\text { Drift } \\
-2.44407 \mathrm{e}-3 \\
\end{array}$ & $\begin{array}{c}\text { Drift } \\
7.85963 \mathrm{e}-5\end{array}$ & & $\begin{array}{c}\text { Perpendicularity } \\
-4.40316 \mathrm{e}-7\end{array}$ & $\begin{array}{c}\text { Constant rotation } \\
-1.13151 \mathrm{e}-5\end{array}$ \\
\hline & & 1 & $\begin{array}{c}\text { Perpendicularity } \\
1.18026 \mathrm{e}-5\end{array}$ & $\begin{array}{c}\text { Linear accuracy } \\
-1.10842 \mathrm{e}-5\end{array}$ & & & & $\begin{array}{c}\text { Bending X } \\
-5.13158 \mathrm{e}-8 \\
\end{array}$ \\
\hline & & 2 & \begin{tabular}{|c|} 
Horizontal bending \\
$2.56579 \mathrm{e}-8$ \\
\end{tabular} & & & & & \\
\hline & \multirow{3}{*}{$\stackrel{\nexists ָ}{=}$} & $\mathbf{0}$ & & & & & & \\
\hline & & 1 & & $\begin{array}{c}\text { Linear accuracy } \\
5.00000 \mathrm{e}-8\end{array}$ & & & & \\
\hline & & 2 & & & & & & \\
\hline & & & $\mathbf{z T x}$ & $\mathbf{z T y}$ & $\mathbf{z T z}$ & $\mathbf{z R x}$ & zRy & $\mathbf{z R z}$ \\
\hline \multirow{9}{*}{ 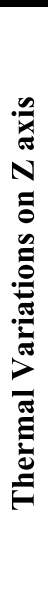 } & \multirow{3}{*}{ 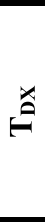 } & 0 & $\begin{array}{c}\text { Drift } \\
-1.26982 \mathrm{e}-3\end{array}$ & & & & $\begin{array}{c}\text { Constant rotation } \\
-1.00595 \mathrm{e}-5\end{array}$ & \\
\hline & & 1 & $\begin{array}{c}\text { Perpendicularity } \\
-3.8381 \mathrm{e}-5\end{array}$ & & & & $\begin{array}{l}\text { Bending X } \\
6.19048 \mathrm{e}-8\end{array}$ & \\
\hline & & 2 & $\begin{array}{c}\text { Bending } \\
3.09524 \mathrm{e}-8\end{array}$ & & & & & \\
\hline & \multirow{3}{*}{$\underline{\theta}$} & 0 & & $\begin{array}{c}\text { Drift } \\
-1.26982 \mathrm{e}-3\end{array}$ & $\begin{array}{c}\text { Drift } \\
3.16875 \mathrm{e}-4\end{array}$ & $\begin{array}{l}\text { Constant rotation } \\
1.00595 \mathrm{e}-5\end{array}$ & & \\
\hline & & 1 & & $\begin{array}{c}\text { Perpendicularity } \\
-3.8381 \mathrm{e}-5 \\
\end{array}$ & $\begin{array}{c}\text { Linear accuracy } \\
-1.95 \mathrm{e}-6\end{array}$ & $\begin{array}{l}\text { Bending Y } \\
-6.19048 \mathrm{e}-8\end{array}$ & & \\
\hline & & 2 & & $\begin{array}{c}\text { Bending } \\
3.09524 \mathrm{e}-8\end{array}$ & & & & \\
\hline & \multirow{3}{*}{$\stackrel{2}{=}$} & 0 & & & & & & \\
\hline & & 1 & & & $\begin{array}{c}\text { Linear Accuracy } \\
5.00000 \mathrm{e}-8\end{array}$ & & & \\
\hline & & 2 & & & & & & \\
\hline
\end{tabular}

the CMM. These terms generate errors in $\mathrm{mm} \cdot \mathrm{K}^{-1}$. Four boxes in table 4 have been grayed out because these variations have no impact on the overall geometry of the machine (constant rotation). All the other variations obtained have been interpreted in terms of corresponding CMM deformations. 
Table 5. Thermal variation considered.

\begin{tabular}{|c|c|c|c|c|c|c|c|c|c|}
\hline Thermal effect & $T_{V X}$ & $T_{H X}$ & $T_{R X}$ & $T_{V Y}$ & $T_{H Y}$ & $T_{R Y}$ & $T_{d x}$ & $T_{d y}$ & $T_{R Z}$ \\
\hline Maximum thermal variations $\left({ }^{\circ} \mathrm{C}\right)$ & 0.3 & 0.3 & 0.4 & 0.05 & 0.05 & 0.3 & 0.05 & 0.05 & 0.4 \\
\hline
\end{tabular}

Table 6. Sphere evaluation-Monte Carlo simulation on MCG.

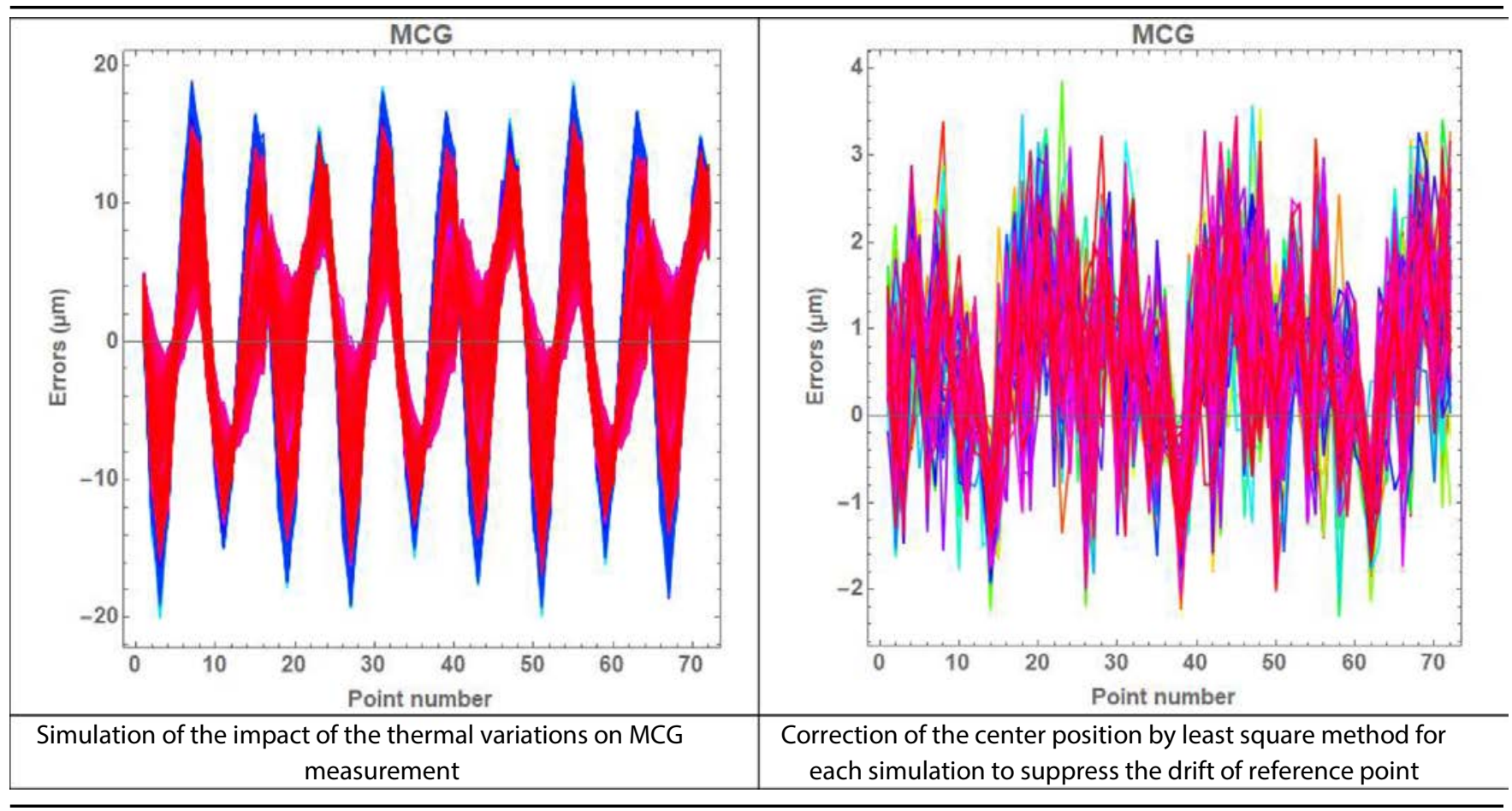

\section{Results and analysis}

The calibration of the CMM geometry was performed by interferometry and electronic levels for rotations, at least for $x R x$ and $y R y$. A specific measurement must be made for $z R z$. The machine was instrumented using temperature sensors (PT 100 wiring in four wires on an Agilent 34972 A power plant) to estimate thermal gradients and axes thermal expansion. The different maximum thermal variations estimated on the CMM are reported in table 5 .

So, it is possible to carry out a Monte Carlo simulation in order to estimate the CMM variations. The results are presented in Appendices I, II and III.

Table 6 presents the effects of the CMM geometrical evolution due to thermal variations on the sphere generated by a Machine Checking Gauge (MCG) of $452 \mathrm{~mm}$ in diameter. These representations correspond to the experimental measurement of 72 regularly distributed points on which a Monte Carlo simulation is carry out to assess the impact of thermal variations on measurement. The left column shows the simulated errors without treatment. In the right column, a least square refocusing was performed on each of the measurements to remove errors related to the fixed point offset. These thermal drift errors, correspond to the main source of errors during thermal CMM evolutions.

\section{Conclusion}

This paper presents a physical method for determining the thermal evolutions of the machine's defects based on an analysis of the basic elements of CMM construction. The correction of the bending of the granite table is well-known but this study generalizes the possibilities for the correction of the machines and allows the problem of drift in the points of reference to be better taken into account.

With this method, it is also possible to account for the deformation of the machine caused by the weight of the measured part (deformation of the granite table) in the evaluation of uncertainties. To achieve this, it is sufficient to calculate the bending of the granite support and to carry out similar types of computations. It is also possible to evaluate the impact of the variation of the air film thickness of the aerostatic bearings.

Table 4 identified defects impacted by gradients and thermal variations around the CMM. This analysis is interesting in the design of a CMM. It also provides a better understanding of the evolution of the CMM defects and in particular the problems of drift. These are important and harmful in the context of the use of a rotary table for example over long periods of time.

Finally, this study (carried out for the French CETIM) forms the base of a MLMCS, which allows us to evaluate the uncertainties of any measurand on CMMs [31]. The MLMCS is carrying out on two levels, namely: 


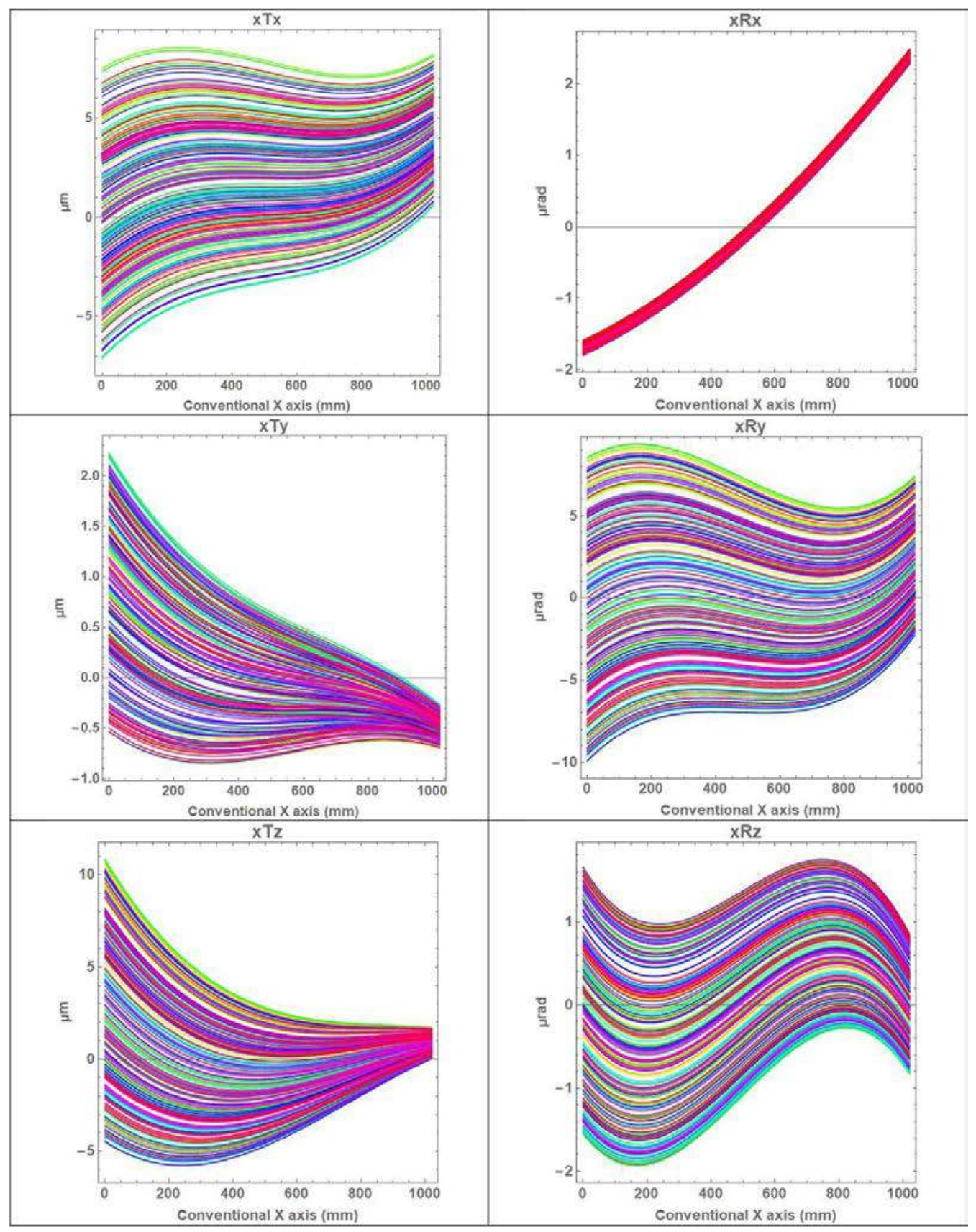

Appendix I. Geometrical evolution on the CMM - $X$-axis. 


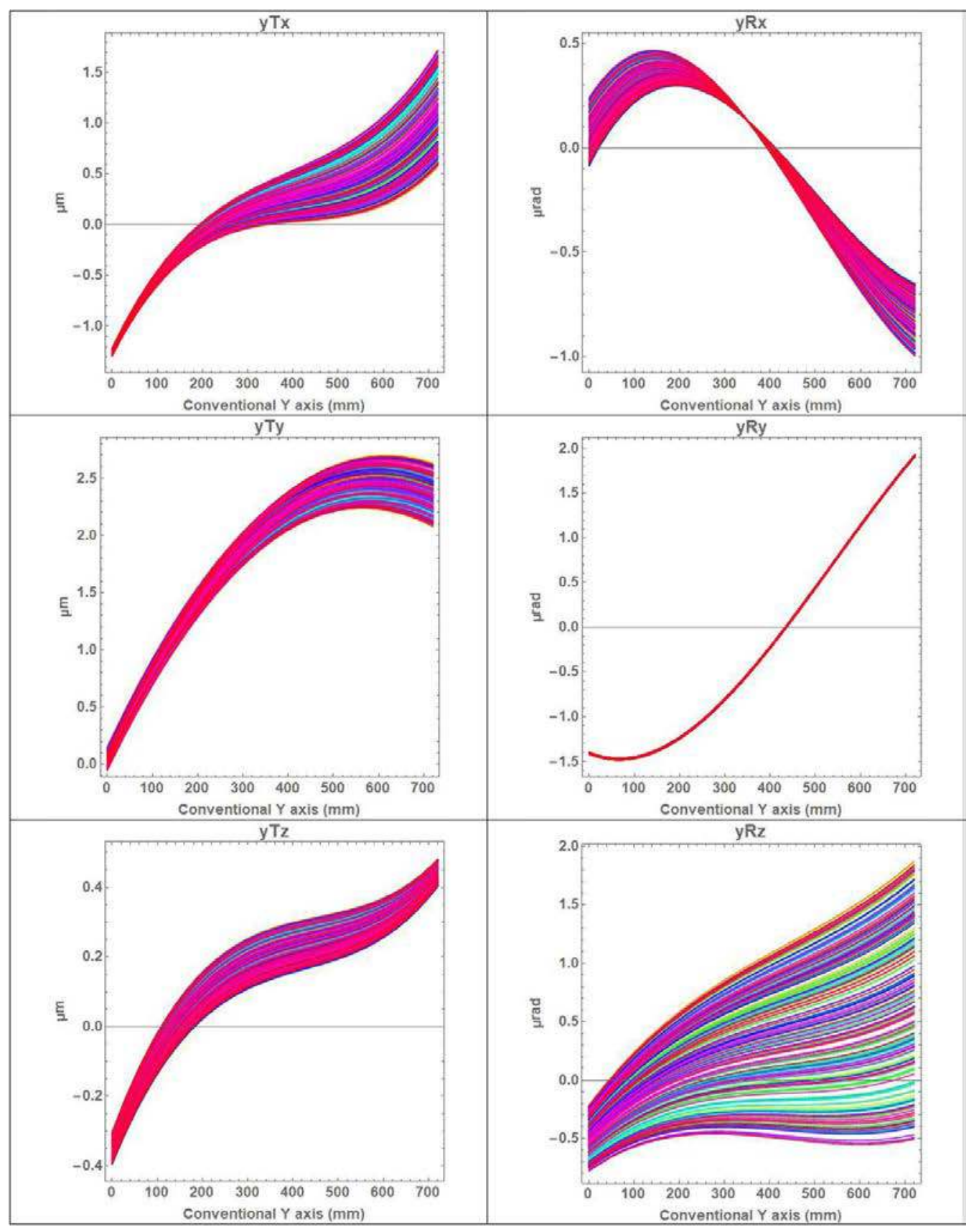

Appendix II. Geometrical evolution on the CMM - $Y$-axis. 


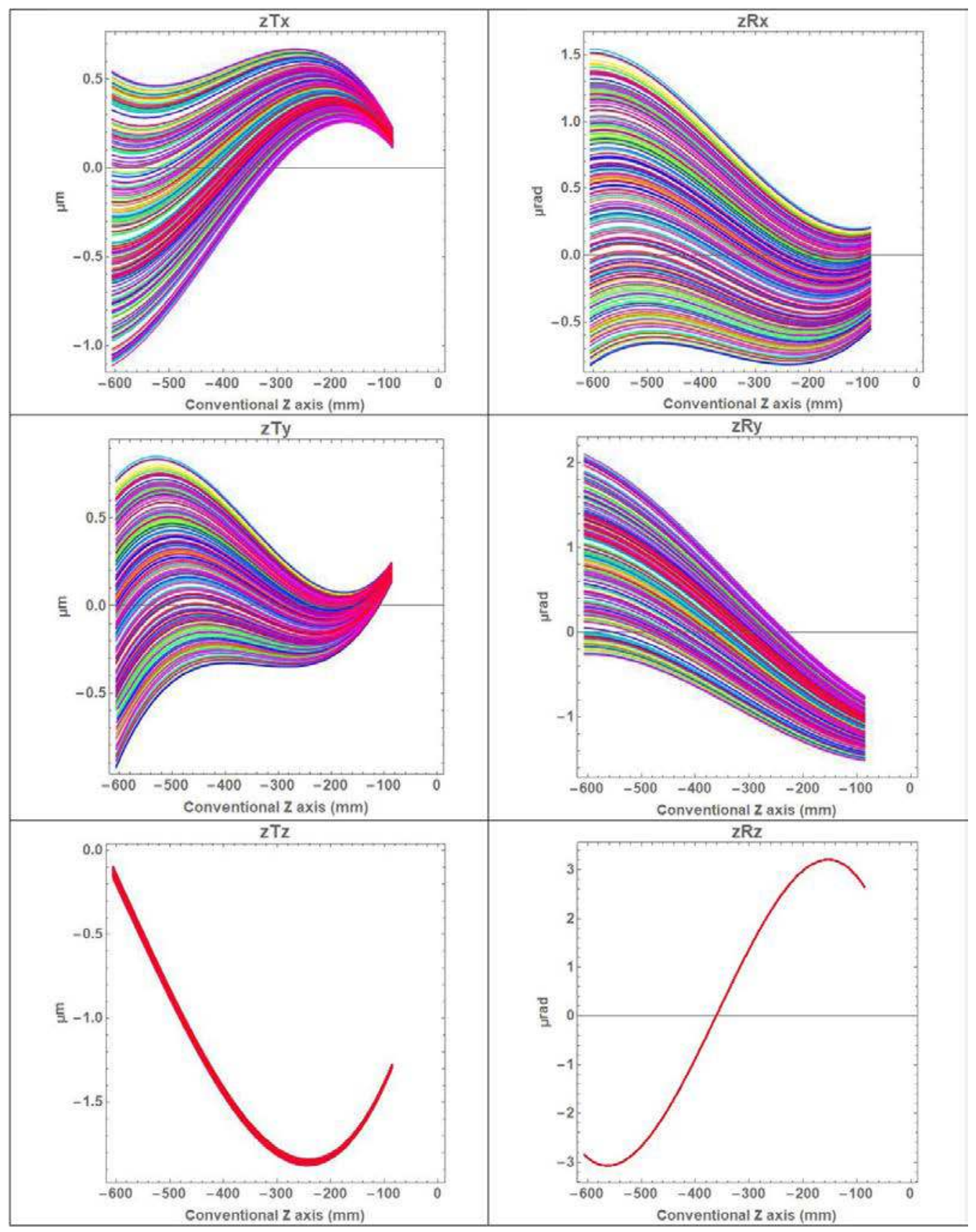

Appendix III. Geometrical evolution on the CMM-Z-axis. 
-The first level takes into account CMM defects and their evolutions caused by thermal variations (the principle topic of this paper) or other reasons. Dynamic effects and defects in the probing system are also added at this level.

-The second level concerns the part and the evaluation of the measurands. This level takes into account the effects related to reference entities, resolutions, repeatability, roughness, uncertainties on the determination of CMM defects.

\section{ORCID iD}

François Hennebelle (D) https://orcid.org/0000-0003-02180925

\section{References}

[1] Bosch J A 1995 Coordinate Measuring Machines and Systems (Boca Raton, FL: CRC Press) pp 24 p 496

[2] ISO 10360-1:2000 Geometrical Product Specifications (GPS) - Acceptance and reverification tests for coordinate measuring machines (CMM) - Part 1: Vocabulary

[3] Schwenke H, Knapp W, Haitjema H, Weckenmann A, Schmitt $\mathrm{R}$ and Delbressine F 2008 Geometric error measurement and compensation of machines-An update CIRP Ann. 57 $660-75$

[4] Technical report BCR EUR 10909 EN 1986

[5] Technical report BCR EUR 13418 EN 1991

[6] Technical report BCR EUR 15304 EN 1993

[7] Cox M G and Harris P M 1993 Assessing fundamental geometric form from measured coordinate data. A K Kochhar (eds) Proc. Thirtieth Int. MATADOR Conf. Palgrave, London

[8] Richter D 2006 Validation of software in metrology Comput. Stand. Interfaces 28 253-5

[9] Busch K, Kunzmann H and Wäldele F 1985 Calibration of coordinate measuring machines Precis. Eng. 7 139-44

[10] Zhang G, Veale R, Charlton T, Borchardt B and Hocken R 1985 Error compensation of coordinate measuring machines CIRP Ann. 34 445-8

[11] Kunzmann H, Trapet E, Wäldele F and Uniform A 1990 Concept for calibration, acceptance test, and periodic inspection of coordinate measuring machines using reference objects CIRP Ann. 39 561-4

[12] Trapet E and Wäldele F 1995 The virtual CMM concept, advanced mathematical tools in metrology World Sci. Publ. Comp. 40 238-47

[13] Trapet E et al 1999 Traceability of coordinate measurements according to the method of the virtual measuring machine, Final Project Report MAT1-CT94-0076, PTB-report F-35, Part 1 and 2

[14] Phillips S D et al 2002 The calculation of CMM measurement uncertainty via the method of simulation by constraints Annals of the 12th Annual meeting of the ASPE Norfolk, VI American Society for Precision Engineering-ASPE pp $443-52$

[15] Trenk M, Franke M and Schwenke H 2004 The "Virtual CMM" a software tool for uncertainty evaluation - practical application in an accredited calibration lab ASPE Proc.: Uncertainty Anal. Meas. Des. (http://doi.org/10.1.1.474.27)
[16] Takamasu K et al 2002 International standard development of virtual CMM (coordinate measuring machine) Tokyo, Japan: NEDO International Joint Research Project (FY 1999 - FY 2001) Final Research Report p 159

[17] Sładek J and Gąska A 2012 Evaluation of coordinate measurement uncertainty with use of virtual machine model based on Monte Carlo method Measurement 45 1564-75

[18] Jakubiec W and Płowucha W 2013 First coordinate measurements uncertainty evaluation software fully consistent with the GPS philosophy Procedia CIRP $10317-22$

[19] Sladek J A 2016 Coordinate Metrology: Accuracy of Systems and Measurements (Berlin: Springer)

[20] JCGM 101:2008 Evaluation of measurement data Supplement 1 to the "Guide to the expression of uncertainty in measurement" - Propagation of distributions using a Monte Carlo method BIPM

[21] Flack D Good Practice Guide No. 130 (Co-ordinate measuring machine, task-specific measurement uncertainties) September 2013 National Physical Laboratory

[22] Bosch J A 1995 Coordinate Measuring Machines and Systems (Boca Raton, FL: CRC Press)

[23] Gomez-Acedo E, Olarra A, Orive J and Lopez de la Calle L N 2013 Methodology for the design of a thermal distortion compensation for large machine tools based in state-space representation with Kalman filter Int. J. Mach. Tools Manuf. $75100-8$

[24] Gomez-Acedo E et al 2015 Method for measuring thermal distortion in large machine tools by means of laser multilateration Int. J. Adv. Manuf. Technol. 80523

[25] Kruth J-P, Vanherck P and Van den Bergh C Compensation of static and transient thermal errors on CMMs 2001 CIRP Ann. 50 377-80

[26] Kruth J-P, Van den Bergh C and Vanherck P 2001 Correcting steady-state temperature influences on coordinate measuring machines J. Manuf. Syst. $19365-74$

[27] Los A and Mayer J R R 2018 Application of the adaptive Monte Carlo method in a five-axis machine tool calibration uncertainty estimation including the thermal behavior Precis. Eng. 53 17-25

[28] Mayr J et al 2012 Thermal issues in machine tools CIRP Ann. 61 771-91

[29] Cuesta E, Alvarez B, Sanchez-Lasheras F and Gonzalez-Madruga D 2015 A statistical approach to prediction of the CMM drift behaviour using a calibrated mechanical artefact Metrol. Meas. Syst. 22 417-28

[30] Balsamo A, Marques D and Sartori S 1990 A method for thermal-deformation corrections of CMMs CIRP Ann. 39 557-60

[31] Hennebelle F, Coorevits T and Vincent R 2015 Multilevel Monte Carlo approach to evaluate the process closer to physics 17th Int. Congress of Metrology hennebel, EDP sciences 02002 Les Ulis

[32] NF E 11-151 2003 Machines à mesurer àtridimensionnelles à portique, Représentation des corrections de géométrie $17 \mathrm{La}$ Plaine Saint-Denis, France: AFNOR In French

[33] Coorevits T Contribution au développement des techniques d'auto-calibrage appliquées aux machines à mesurer tridimensionnelles Thésis of Ecole Nationale Supérieure d'Arts et Métiers90 ENAM 0003 ch 5 pp 13-14 